\title{
Mulher cuidadora, homem arredio: diferenças de gênero na promoção da saúde masculina
}

\section{Fabíola Rohden}

\section{(2) OpenEdition \\ 1 Journals}

Edição electrónica

URL: http://journals.openedition.org/aa/658

DOI: 10.4000/aa.658

ISSN: 2357-738X

Editora

Programa de Pós-Graduação em Antropologia Social (UnB)

\section{Edição impressa}

Data de publição: 1 junho 2014

Paginação: 125-150

ISSN: 0102-4302

\section{Refêrencia eletrónica}

Fabíola Rohden, «Mulher cuidadora, homem arredio: diferenças de gênero na promoção da saúde masculina», Anuário Antropológico [Online], v.39 n. 1 | 2014, posto online no dia, consultado o 28 abril 2021. URL: http://journals.openedition.org/aa/658 ; DOI: https://doi.org/10.4000/aa.658

Este documento foi criado de forma automática no dia 28 abril 2021.

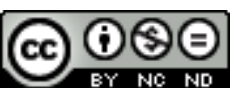

Anuário Antropológico is licensed under a Creative Commons Atribuição-Uso Não-Comercial-Proibição de realização de Obras Derivadas 4.0 International. 


\title{
Mulher cuidadora, homem arredio: diferenças de gênero na promoção da saúde masculina
}

\author{
Fabíola Rohden
}

\section{NOTA DO EDITOR}

Recebido em: 01/11/2013

Aceito em: 13/03/2014

\section{“Homens: participem! Divulguem! Mulheres: motivem seus filhos, maridos, pais, amigos!"}

1 Este artigo discute como determinadas diferenças de gênero são acionadas nos recentes investimentos em torno da medicalização da saúde e da sexualidade do homem através de um evento singular: a Caravana pela Saúde Masculina. Esta iniciativa consistiu em uma campanha de conscientização em prol da saúde, promovida pela Sociedade Brasileira de Urologia (SBU), com apoio financeiro da indústria farmacêutica Eli Lilly, que percorreu diversas cidades brasileiras no ano de 2010. Inicio com um breve relato etnográfico acerca da passagem da Caravana pela cidade de Porto Alegre. ${ }^{1}$

2 No dia 25 de julho de 2010, um domingo ensolarado, quem percorresse a extensão do Parque da Redenção, em Porto Alegre, palco tradicional de manifestações políticas e culturais, encontraria, além da presença de militantes e candidatos às eleições daquele ano, duas outras presenças significativas. A primeira era mais uma edição da campanha contra o câncer de mama, reunindo um grupo considerável de mulheres vestindo camisetas cor-de-rosa que, muito animadas, agitavam suas bandeiras e acompanhavam um caminhão, também "vestido" de rosa, que fazia as vezes de carro de som. As participantes, em sua maioria mulheres adultas, também acompanhadas de homens de 
várias idades e crianças, demonstravam grande comprometimento com a causa. A marcha prosseguia pela área mais agitada e nobre do parque, sendo notada por todos que passavam.

3 Promovendo um contraste interessante, do outro lado do parque estava estacionada uma enorme carreta, ladeada por tendas brancas e cercada por faixas de isolamento, na frente da qual se organizava uma fila de umas 30 pessoas, a maioria homens. Toda a extensão lateral da carreta era ocupada por duas imagens que davam a impressão de contraste e também de continuidade. Do lado esquerdo, via-se um homem, sentado de costas, em uma posição de prostração e um tanto cabisbaixo. Do lado direito, aparentemente o mesmo homem, de cerca de 40 anos, aparecia sorridente, abraçado a uma mulher, também muito sorridente. Deduzimos que devem ser um casal, já que tem destaque na cena a aliança usada pelo marido. Os dois correspondem ao perfil estético comumente valorizado em campanhas publicitárias, com cortes modernos de cabelo e roupas descontraídas. Em destaque, à esquerda, com letras vermelhas, vemos o slogan "Movimento pela saúde masculina". No centro, em preto, as seguintes frases: "Não vire as costas para a disfunção erétil, a andropausa e as doenças da próstata. Esses problemas têm tratamento. Ter a sua vida de volta é mais fácil do que você imagina". Na parte de baixo, em branco, temos os logotipos da Sociedade Brasileira de Urologia e do laboratório Eli Lilly.

4 Tudo dava a impressão de ser muito organizado e profissional, impressão corroborada pelas informações prestadas pelos rapazes, jovens e fortes, que organizavam o acesso. Eram todos de uma agência local de promoção e organização de eventos, e auxiliavam a equipe de saúde, composta por três urologistas, uma psicóloga e um grupo de enfermeiros, além de um fotógrafo e outros ajudantes. Ao se aproximar da fila, qualquer pessoa era informada de que estavam sendo realizadas consultas urológicas, sendo disponibilizadas 120 senhas por dia. A ação em Porto Alegre ocorreu entre os dias 22 e 25 de julho de 2010, entre 9 da manhã e 5 horas da tarde. ${ }^{2}$

$5 \mathrm{Na}$ fila, homens de várias idades, alguns acompanhados de suas companheiras, recebiam um panfleto informativo que reproduzia as mesmas informações do caminhão e acrescentava em destaque: "Homens: participem! Divulguem! Mulheres: motivem seus filhos, maridos, pais, amigos!". Na sequência, abaixo do slogan "Participe e celebre a saúde", acrescentavam-se as seguintes informações:

A Organização Mundial da Saúde (OMS) coloca a sexualidade saudável como um dos cinco principais indicadores de qualidade de vida de uma população. Por isso, a Sociedade Brasileira de Urologia reconhece e quer celebrar a importância de uma vida saudável. Se você e sua(seu) companheira(o) têm mais de 40 anos, compareçam à Unidade Móvel do Movimento pela Saúde Masculina e ganhem na hora uma fotografia artística do casal, realizada por um fotógrafo profissional.

6 No verso do folheto, ainda descobrimos que:

O Movimento pela Saúde Masculina é uma iniciativa da Sociedade Brasileira de Urologia com o objetivo de conscientizar a população para a necessidade da prevenção e o tratamento de doenças do homem, como a disfunção erétil, a andropausa e as doenças da próstata.

O câncer da próstata é o câncer mais frequente do homem, representando mais de $40 \%$ dos tumores que atingem os homens acima de 50 anos. O diagnóstico precoce é fundamental para um tratamento bem-sucedido. Cerca de $40 \%$ dos homens acima de 40 anos apresentam algum grau de dificuldade de ereção. Já existem inúmeras opções de tratamento. 
A andropausa afeta de 10 a $30 \%$ dos homens acima de 60 anos. O tratamento melhora os sintomas e a qualidade de vida.

A Unidade Móvel do Movimento pela Saúde Masculina está percorrendo o Brasil oferecendo orientação médica gratuita para homens com mais de 18 anos de idade (grifos no original).

7 Depois da espera na fila, os homens eram encaminhados para uma das tendas, na qual assistiam a um filme explicativo sobre as referidas "doenças", passando em seguida pela triagem com a equipe de enfermeiros e seguindo para os consultórios montados dentro da carreta. Enquanto isso, somente aqueles acompanhados por mulheres eram convidados a entrar no pequeno estúdio, também instalado permanentemente no caminhão, para fazerem a "fotografia artística do casal", antes preenchendo e assinando as fichas de concessão de uso da imagem. Segundo os organizadores, essas fotos seriam usadas em congressos médicos. Os homens que saíam dos consultórios traziam nas mãos folhas com informações, receitas de medicamentos ou encaminhamentos para exames.

Voltando ao contraste com a outra campanha em cena naquele dia: se no caso das mulheres tratava-se sobretudo de chamar a atenção pública para a necessidade de conscientização para um problema de saúde, os homens, por sua vez, já eram diretamente convidados a se submeterem a uma consulta médica. É curioso também o uso do termo "movimento" pela saúde masculina; ao contrário do que se poderia imaginar, não refletia uma organização política de base, voltada à reivindicação de direitos, mas a iniciativa de uma associação profissional. Não é objetivo aqui alongar esse rápido contraste, mas é impossível deixar de notar essas diferenças que apontam para um fenômeno mais geral que é a recente promoção sobre a saúde do homem. ${ }^{3}$

9 Contudo, este instante etnográfico brevemente relatado chama a atenção, em particular, por dois aspectos que aparecem nos slogans da Caravana. Na frase "Ter a sua vida de volta é mais fácil do que você imagina", temos o primeiro deles. Trata-se de uma referência à ideia de que o sexo corresponde à própria noção de vida; de que se um homem tem problemas relacionados ao desempenho sexual, estaria sem vida ou, pelo menos, sem ter 0 controle sobre ela. ${ }^{4}$ Já na chamada "Homens: participem! Divulguem! Mulheres:motivem seus filhos, maridos, pais, amigos!", vemos em cena uma referência privilegiada ao papel das mulheres. A campanha parece tão direcionada a eles, alvos da intervenção, quanto a elas, capazes ou responsáveis por levá-los ao médico. Além disso, o fato de que somente aqueles acompanhados por uma mulher poderiam ter a "cortesia" de fazer a "foto artística do casal" também revela o reforço de uma perspectiva heteronormativa. Ou seja, a presença das mulheres neste cenário serve não apenas para indicar uma referência ao modelo tradicional de cuidado feminino, mas também para assegurar a sexualidade, exclusivamente heterossexual, associada à saúde dos homens.

10 A partir deste cenário, pretendo discutir quais referências de gênero e sexualidade são acionadas no recente processo de medicalização masculina que vem se consolidando nas últimas décadas. Para tanto, sugiro que a Caravana pela Saúde Masculina se constitui em um evento privilegiado que ilustra esse processo. Posteriormente, farei uma descrição mais pormenorizada e contextualizada desta iniciativa por meio de uma série de estratégias metodológicas empregadas. À etnografia de eventos somaram-se entrevistas com profissionais da área médica, análise de documentos e de sítios 
institucionais na internet. Antes disso, contudo, faço referência aos conceitos que podem ser úteis para o entendimento desse processo.

\section{Tecnologias de intervenção e a mobilização de diferenças de gênero}

11 A perspectiva analítica empregada está centrada na ideia de que uma campanha de promoção da saúde, como a Caravana, pode ser entendida como uma tecnologia de intervenção que articula diferentes fatores. A concepção mais geral centra-se na percepção dos fenômenos sociais como redes complexas e heterogêneas, constituídas por agentes ou mediadores que se engajam nos eventos a partir de distintos interesses e posições. ${ }^{5}$ Nesse sentido, o processo de produção deste tipo de tecnologia de intervenção em saúde pode envolver desde a promoção de certos conceitos, diagnósticos, valores, criação de procedimentos, exames, recursos e itinerários terapêuticos até a participação de profissionais, companhias farmacêuticas, instâncias do governo, meios de comunicação e, é claro, os distintos "públicos-alvo" pretendidos. Analisar, portanto, um evento assim supõe que sejam investigados quais processos, interesses, recursos e agentes estão em cena e de que forma são mobilizados.

No que se refere à tecnologia utilizada pela Caravana pela Saúde Masculina, que tem a pretensão de conscientizar a população para a necessidade da prevenção e o tratamento de doenças do homem, tão ou mais importante que os meios ou recursos materiais por ela empregados, como o caminhão com consultórios que viabilizam as consultas, são os conceitos ou as ideias-chave acionados na divulgação e na realização da campanha. E é exatamente em torno da produção deste tipo específico de narrativa que é possível perceber como determinados marcadores associados a gênero e sexualidade são mobilizados.

Esta preocupação remete a uma discussão que acredito ser importante não apenas para os estudos de gênero, sexualidade e saúde, mas também para as investigações centradas na ciência e na tecnologia. Trata-se da questão mais geral acerca da produção de novos artefatos tecnológicos e sua relação com dimensões especificamente culturais como, por exemplo, a associação com questões identitárias ou subjetivas. A forma como diferentes desenvolvimentos tecnocientíficos - desde os diagnósticos até os fármacos articulam-se com valores sociais e marcadores identitários em nossa sociedade ainda está por ser mais bem explorada. 0 processo de medicalização da saúde do homem e sexualidade parece ser um caso exemplar para se refletir sobre isso.

Explorando as dificuldades envolvidas na produção de um contraceptivo masculino, Oudshoorn $(2003,2004)$ salienta exatamente a relevância desta associação entre tecnologia e cultura. $\mathrm{O}$ fato de a chamada "revolução contraceptiva" ter ficado restrita a métodos femininos reflete uma conjuntura na qual o que predominou foi a falta de sustentação da ideia de que os métodos masculinos seriam viáveis e aceitos, em um quadro em que se destacam agentes tão variados como a Organização Mundial de Saúde, laboratórios farmacêuticos, governos de países como China e Índia, agências de planejamento familiar e feministas. Do ponto de vista tecnológico, vários caminhos eram possíveis mas, da perspectiva da aceitação social, os impedimentos predominaram e influenciaram, por exemplo, a demora e a exígua participação das indústrias farmacêuticas no processo, já que duvidavam da aceitabilidade deste tipo de produto no mercado. Dessa forma, "a assimetria na prática contraceptiva foi materializada em 
instituições, profissões médicas, técnicas de laboratório, produtos químicos e farmacêuticos" (Oudshoorn, 2004:351, tradução minha).

A partir deste quadro, a autora sustenta que os estudos envolvendo gênero e tecnologia têm mostrado como as tecnologias exercem um papel de destaque ao ajudarem a estabilizar ou a desestabilizar as convenções de gênero. Inspirada na concepção de Butler (1995) do gênero como repetição ritualizada de convenções, Oudshoorn (2004) sinaliza que as tecnologias são fundamentais nesse processo, criando novas performances de gênero ou reforçando as já existentes. As diferenças em torno da questão da contracepção para homens e mulheres ao longo do século XX podem ser entendidas por meio do conceito de "tecnossociabilidade". De acordo com a autora, desta vez inspirada em Rabinow (1992), tecnossociabilidade "sugere que as pessoas constroem identidades coletivas baseadas em experiências compartilhadas com tecnologias específicas" (Oudshoorn, 2004:353, tradução minha). No caso estudado por ela, a ideia da mulher como responsável pela contracepção tornou-se a "narrativa cultural dominante, materializada em tecnologias contraceptivas, em movimentos sociais, e identidades de gênero de mulheres e homens" (Oudshoorn, 2004:353, tradução minha).

16 As tecnologias, nesse sentido, "não refletem propriedades essencialistas dos corpos, mas são os resultados materializados de negociações, processos de seleção, contingências e escolhas tecnológicas, incorporando valores e práticas social e culturalmente constituídas" (Oudshoorn, 2004:352, tradução minha). E como alguns estudos têm mostrado, através do conceito de "representações dos usuários", cientistas e engenheiros (e, poderíamos acrescentar, médicos) configuram usuários e contextos de uso como componentes importantes do processo de desenvolvimento tecnológico. Contudo, não se trata meramente de definir a relação de dependência entre usuários e tecnologia, ou de explicitar a questão das competências e ações dos usuários em face do seu uso, mas de considerar a dimensão das identidades, que têm um papel relevante na constituição da viabilidade cultural da tecnologia (Oudshoorn, 2003:12).

Oudshoorn (2004) pondera ainda que os estudos sociais da tecnologia e mesmo o emprego do conceito de redes sociotécnicasnão têm dado a devida atenção às normas $\mathrm{e}$ aos valores culturais que estruturam a sociedade e conformam as relações e as experiências das pessoas, ficando demasiadamente restritos ao âmbito meramente social. Isso fez com que a dimensão de gênero, por exemplo, não tivesse sido devidamente considerada nos processos de inovação tecnológica. Para a autora, "incluir as dimensões culturais da inovação tecnológica não se refere somente a conceitualizar a tecnologia em termos de redes de técnicas, conhecimento, instituições, expertos e grupos sociais, mas também incluir as relações entre tecnologias e identidades subjetivas dos usuários" (Oudshoorn, 2004:353, tradução minha).

Outra ponderação importante se refere ao fato de que há diferenças consideráveis entre tecnologias que requerem a criação de redes sociotécnicas novas ou pressupõem drásticas transformações em redes já estabelecidas e aquelas que seguem rotinas e práticas já bem desenvolvidas. Nessa linha, Oudshoorn (2003) lança mão dos conceitos de "trajetória de dependência" e "trajetória de criação". o primeiro remete a como as tecnologias futuras se associam às tecnologias já existentes e aos prévios investimentos materiais, sociais e simbólicos. O segundo aponta para novas perspectivas tecnológicas que representam rompimentos com o passado. De qualquer forma, o importante a ser 
considerado é a relação constante entre estrutura e agência, ou reprodução e criação, na análise da vinculação entre tecnologias e seus enquadramentos culturais.

Sugiro que os elementos discutidos podem ser apropriados de forma pertinente para analisar a Caravana pela Saúde Masculina e a construção de uma narrativa bastante específica no que concerne às relações de gênero e àsconcepções de sexualidade empregadas. Para prosseguir na discussão, contudo, é necessário descrever mais acuradamente a Caravana.

\section{A Caravana pela Saúde Masculina e seus registros}

20 A Caravana pela Saúde Masculina foi a atividade central do Movimento pela Saúde Masculina, campanha realizada entre março e setembro de $2010 .{ }^{6}$ Tratou-se de uma iniciativa idealizada pela Sociedade Brasileira de Urologia (SBU), com apoio financeiro da indústria farmacêutica Eli Lilly. A Caravana pela Saúde Masculina percorreu muitas capitais e outras cidades brasileiras através da utilização de uma carreta adaptada em consultório médico. A campanha ainda contava com anúncios, comerciais de televisão e peças publicitárias, além de ter havido a criação de um sítio específico ${ }^{7}$ que agregou todo o material produzido no decorrer do evento. De acordo com as informações dos organizadores, foram contabilizados 78 dias de atendimentos da Caravana pela Saúde Masculina, em um total de 26 eventos, realizados em 22 cidades. ${ }^{8}$ Mais de 10 mil homens foram atendidos em locais públicos, como praças, parques e estacionamentos de centros comerciais ("Chegou nos 10.000 e na hora de partir", 05/09/2010). ${ }^{9}$

o caminhão que traçou o país contava com três consultórios para atendimentos médicos; uma sala para exames e pré-consultas; uma recepção; uma sala de estúdio para fotos; outro estúdio, dotado de equipamento de som e luz, destinado à obtenção de depoimentos de pacientes; uma tenda para deficientes físicos, além de uma tela de plasma para exibição de vídeos temáticos. Em seu exterior adaptava-se uma tenda para estruturar as filas de atendimento. A Caravana pela Saúde Masculina contava com 11 profissionais fixos, grupo que era complementado com a presença de médicos e produtores locais. Ao menos dois enfermeiros, o fotógrafo, a psicóloga e alguns promotores eram profissionais constantes na atuação da Caravana. Os médicos urologistas que atendiam nesta campanha, bem como alguns produtores, variavam de acordo com o local de atuação da Caravana. Geralmente se tratava de médicos urologistas filiados à SBU do estado no qual eram realizados os atendimentos ("Urologistas atenderão homens no Parque da Cidade", 27/05/2010; "Equipe em Vitória", 22/04/2010).

Os atendimentos eram realizados de acordo com a distribuição de 120 senhas, concedidas a partir da organização de uma fila única por ordem de chegada desde as 8 horas da manhã. 0 procedimento geral dos atendimentos consistia, primeiramente, em uma conversa dos pacientes com os enfermeiros para, na sequência, serem encaminhados ao urologista e, possivelmente, também à psicóloga ("Urologistas atenderão no parque da cidade", 27/05/2010). Após a orientação, o paciente poderia ser convidado a prestar um depoimento sobre a sua experiência no atendimento e a realizar uma "foto artística", executada por um fotógrafo profissional que acompanhava a Caravana, desde que estivesse acompanhado por sua mulher, companheira ou namorada e tivesse mais de 40 anos de idade. Como já foi dito, apenas um certo modelo de casal, formado por um homem e uma mulher, conformado aos 
padrões heteronormativos, poderia ser retratado e servir de registro e propaganda para o Movimento. ${ }^{10}$

Além da etnografia do evento em Porto Alegre e do acesso a diferentes fontes de informação sobre a campanha, considero que os dados contidos no sítio do Movimento são especialmente relevantes. Foram produzidos ou editados a partir da perspectiva dos realizadores, que tinham objetivos claros em relação à chamada de atenção para os problemas de saúde masculinos, notadamente em função das três categorias citadas: disfunção erétil, problemas da próstata e andropausa. Se por meio da observação in loco da Caravana podemos ter acesso imediato ao cenário dos vários atores envolvidos e em ação, com os registros textuais e fotográficos é possível aprofundar a investigação das concepções envolvidas por trás da realização do evento. Antes de prosseguir na análise propriamente dita, faz-se necessário apresentar as características do sítio com mais detalhes.

Na página de abertura do sítio do Movimento pela Saúde Masculina, apresentavam-se as principais subdivisões, que indicavam, inclusive, os aspectos mais privilegiados pelos organizadores. O link "Movimento" fornecia dados gerais acerca da campanha ("Sobre o Movimento", "Caravana", "Campanha", "Divulgue"). Já os demais se referiam às doenças focadas pelo evento. Neste caso, "Disfunção Erétil" tinha o maior destaque, com informações gerais sobre esta categoria de diagnóstico; um teste para avaliação do visitante do sítio acerca de seu grau de disfunção erétil; possibilidades de tratamento (quadro organizado de acordo com diferentes tipos de medicamentos para disfunção erétil - Cialis, Cialis Diário, Levitra, Viagra, Helleva - em relação a seus efeitos, como "eficácia", "início de ação", "duração de ação", "interação com alimentos", "eventos adversos"); e depoimentos de homens acerca de suas experiências com a disfunção erétil.

O link "Outras Doenças" referia-se às "Doenças da Próstata" e à "Andropausa". Quanto às doenças da próstata, eram fornecidas informações referentesa: "o que é câncer da próstata"; "o que causa"; "o que é hiperplasia prostática benigna". Ainda eram disponibilizados depoimentos de homens sobre suas experiências com doenças da próstata; informações sobre tratamentos para câncer de próstata e hiperplasia prostática benigna; e um teste que servia como referência para que o leitor do sítio tomasse decisões relativas às doenças da próstata. Sobre a andropausa eram fornecidas informações acerca do que é a andropausa e o que causa esta doença; dados sobre tratamentos de reposição hormonal; e depoimentos de pacientes acerca de suas experiências com a andropausa.

Havia também uma se
ção de imprensa que se subdividia em "newsletter" (cadastro para receber notícias); “ releases"; "matérias" (material de imprensa oriundo de rádio, jornal, televisão e internet sobre o Movimento pela Saúde Masculina); "Portavozes" (lista e informações de médicos participantes do Movimento pela Saúde Masculina); "download" (onde se encontravam disponíveis fotos dos consultórios da Caravana pela Saúde Masculina); "podcast" (com arquivos diversos, como as entrevistas do jogador de futebol "Kleber Gladiador" e do técnico "Felipão" para o Movimento pela Saúde Masculina); "conferência" (vídeo da conferência do lançamento da campanha Movimento pela Saúde Masculina) e "links" (também relacionados ao Movimento). Já o link "Encontre um médico" consistia em um sistema de buscas por urologistas que reforçava a ideia de que a orientação médica é insubstituível. Através de informações 
relativas a "nome", "estado (UF)", "cidade" e "CEP", este dispositivo de busca selecionava o médico urologista mais próximo do usuário em questão. ${ }^{11}$

Além disso, tem destaque o chamado "Blog da Caravana", um espaço virtual no qual se efetivou o registro frequente de informações relativas ao andamento da Caravana pela Saúde Masculina ao longo das cidades que constituíram seu percurso. O Blog da Caravana tinha o total de 247 registros, também chamados de postagens ou posts, como depoimentos, notícias, sugestões de práticas para uma vida mais saudável e fotos dos atendimentos. No espaço do blog, apareciam diferentes tipos de "postagem", que foram organizados, para efeito de análise em: a) informações sobre a Caravana e depoimentos de médicos e profissionais de saúde participantes (131 registros); b) depoimentos de usuários/pacientes e acompanhantes (97 registros); e c) material de imprensa reproduzido (19 registros).

Para este artigo, privilegiei os depoimentos de médicos e "pacientes", como são chamados, que estiveram presentes nos eventos, já que a meta era priorizar os discursos produzidos em torno da existência de cuidado ou atenção à saúde masculina, enfatizando as atitudes relatadas pelos próprios usuários e médicos. Quanto aos três temas-alvo do Movimento, é importante mencionar que as doenças da próstata (tema de 44 posts) e a disfunção erétil (33 posts) apareciam com muito mais frequência do que a andropausa (apenas seis posts). Isto apontaria para certa insuficiência na divulgação da andropausa naquele momento, ${ }^{12}$ em contraste com o destaque dado às doenças da próstata, tema que já há algum tempo é reconhecido como alvo de preocupações importantes no que se refere à saúde do homem. Também refletiria os pesados investimentos, um tanto mais recentes, dos urologistas e do Movimento pela Saúde Masculina na disfunção erétil.

De um modo geral, todo o conteúdo exposto no sítio do Movimento e nos eventos da Caravana, seja tratando de disfunção erétil, seja das doenças da próstata ou da andropausa, insiste na constatação de que os homens tradicionalmente não cuidam de sua saúde e, em consequência, estariam correndo sérios riscos. Isto se deve a um conjunto de fatores que poderiam ser chamados de "culturais", como medo, vergonha, preconceito, ignorância. Em contraste, as mulheres aparecem como privilegiadas por contarem com uma vasta rede de atendimento e também como aliadas imprescindíveis, porque, acostumadas com a responsabilidade do cuidado com a saúde da família, conduziriam os homens ao médico. Além disso, menciona-se com veemência a falta de profissionais urologistas ou de serviços especializados no Sistema Único de Saúde (SUS) que garantissem e facilitassem o acesso dos homens a programas de conscientização, exames e tratamentos. No que se refere mais especificamente à sexualidade, nota-se a presença marcante de uma concepção centrada na potência sexual masculina, ou mais precisamente, a capacidade de ereção, que seria sempre alvo de preocupações entre os homens. Em continuidade, a prática sexual é pensada pressupondo a existência exclusiva de relações heterossexuais e estáveis, focadas na penetração vaginal.

Algumas observações mais detalhadas ajudam a demonstrar a construção desse discurso. É importante ressaltar que o tratamento dado ao material presente no sítio do Movimento procura destacar os aspectos gerais ou o tom central adotado na elaboração dessa "narrativa" construída em torno da saúde do homem. Com isso, não se pretende perseguir a veracidade dos depoimentos de "pacientes" e profissionais de saúde participantes, ou ir em busca do que não foi dito pelo Movimento. Mas exatamente considerá-lo como um lócus de produção de um discurso público que pretende 
determinados objetivos e que é elaborado tendo como pressuposto um certo tipo de público-alvo. Embora seja possível notar alguma variação nos tipos de informações e depoimentos retratados, a análise fez sobressair perspectivas que, suponho, são focos e estratégias centrais do Movimento.

\section{0 protagonismo atribuído às mulheres}

31 Como foi possível perceber pela descrição do evento da Caravana em Porto Alegre, as mulheres apareciam com muito destaque nesta iniciativa. Por meio dos registros no sítio da Caravana, descortina-se toda uma série de variações importantes que qualificam esta participação. Uma análise geral dos temas frequentes nos registros permitiu identificar a presença significativa de referências às mulheres $e$, por vezes, às famílias. A menção direta ao "fato" de que as mulheresest

ão mais habituadas a procurar o médico, um exemplo a ser seguido pelos homens, foi alvo de destaque em 35 posts. Na mesma direção, enfatiza-se o papel ativo das mulheres, levando ou acompanhando homens, nos eventos da Caravana. O Blog descreve sua presença, ao lado de maridos, pais e outros familiares, em 36 relatos. ${ }^{13}$

Contudo, para além desses números, o que chama mais a atenção é o tom utilizado para descrever as diferenças entre os gêneros no que se refere aos cuidados em saúde. Os títulos escolhidos pelos editores do Blog para alguns registros já indicam a função feminina de levar os homens ao médico: "Trazido pelo braço" (14/04/2010), "Homem é frouxo" (07/05/2010), "Obedece quem tem juízo" (15/08/2010), "Empurrãozinho inicial” (19/08/2010), “Tudo em família” (28/05/2010), “A conscientização que vem das fábricas e do lar" (11/08/2010).

33 Além disso, é importante mencionar que na entrevista coletiva à imprensa, em 25/02/2010, que marcava o lançamento da Caravana, o presidente da SBU naquele momento, o urologista Modesto Jacobino, enfatizava exatamente esta diferença de cuidado entre homens e mulheres. Segundo o médico, "o homem é arredio à consulta médica" e os brasileiros teriam a "dificuldade e o tabu" de procurar um médico em função da crença de que doença seria sinônimo de fraqueza. ${ }^{14}$ Já o registro postado em 03/04/2010era intitulado exatamente "Resistência" e fazia referência ao fato de que, para a Sociedade Brasileira de Urologia, "Muitos homens ainda resistem a fazer exames e consultas médicas periódicas. Mudar esse comportamento é nosso principal objetivo" ("Resistência", 03/04/2010).

34 A concepção da mulher como figura central e exemplar nos atendimentos promovidos na Caravana pela Saúde Masculina centra-se no estereótipo da mulher como cuidadora e responsável pela atenção à saúde de toda a família. Contudo, esta noção mais geral se decompõe em algumas especificidades, dependendo do foco em questão. Esta modulação, percebida sobretudo em função do contraste entre as preocupações com as doenças da próstata e com as disfunções sexuais, constitui um dos aspectos importantes revelados a partir da análise dos registros.

\section{a) "Trazido pelo braço"}

35 O primeiro conjunto de observações que se segue diz respeito à descrição de situações nas quais as mulheres levaram os homens até a Caravana principalmente em virtude de 
temores associados aos problemas da próstata. $\mathrm{O}$ relato intitulado "Obedece quem tem juízo" (15/08/2010) ilustra de forma exemplar a maneira pela qual é apresentada a participação das mulheres durante a Caravana pela Saúde Masculina:

Sr. P., ${ }^{15} 60$ anos, soldador, não teve escolha. Ele teve que pular da cama cedo logo no fim de semana e não importava se estava frio ou garoando, sua esposa, Sra. D., 49 anos, promotora de vendas, o arrastou até a carreta do Movimento pela Saúde Masculina e às 7 h20 eles estavam na fila [...]. Ele confessa que nunca teve muito tempo para se cuidar, além da pouca vontade, mas depois que conheceu a esposa, procura se cuidar mais "até porque ela me arrasta, me incentiva, às vezes eu tenho preguiça, mas ela me leva. Quem tem juízo, obedece, né?!”.

Neste caso, o receio em relação ao câncer de próstata surge como motivação importante, ao lado da referência à associação entre amor e cuidado: "Mas o motivo de tanta preocupação, além do conhecimento da importância da prevenção, é que ela perdeu seu pai, que faleceu por causa do câncer de próstata. Ela conta que ele nunca se cuidou e nunca deixou que os filhos o levassem ao médico por pura ignorância. Ela lamenta a perda e diz que quem ama, cuida e por amar muito seu marido, ela o trouxe até a carreta" ("Obedece quem tem juízo", 15/08/2010).

37 A responsabilidade da mulher como cuidadora, sua persistência e poder de persuasão diante de um homem que é "naturalmente" resistente é descrita também em outro caso:

A Sra. V., assistente de marketing, teve que usar o seu poder de persuasão para convencer o seu marido, Sr. M., a passar pelo atendimento e isso começou em março, quando a carreta do Movimento esteve em São Paulo pela primeira vez. Ela ficou sabendo pela televisão, mas como não podia ir até o Parque da Luz naqueles dias, resolveu acompanhar o movimento pelo site e pelo blog. Deixou anotado na agenda os dias em que a carreta do Movimento voltaria a São Paulo e na última sexta feira (25), falou para o marido:"Vamos lá!” E ele respondeu: "Vamos ver..." Mas ela não deixou passar: "Vamos ver nada, já está visto e já está marcado. Vamos lá sim!". Não teve como o Sr. M. dizer não. "Convenci meu marido, apesar da resistência dele que acho que é normal para todos" ("Uma leitora do blog", 29/08/2010).

38 Na mesma direção, temos ainda o registro que trata da Sra. N., que "não quis esperar o marido completar 40 anos e resolveu trazê-lo até a Caravana do movimento, já que seu sogro foi diagnosticado com câncer". Na sequência, o post descreve a sua trajetória com os exames do marido em busca de uma consulta com um médico urologista:

Há três meses andando com os exames do seu marido, o Sr. B. B., 39 anos, ela conta que é muito difícil marcar uma consulta na rede pública e o exame mais importante que ele precisa fazer ainda não conseguiu [...]. Sempre buscando se informar, a Sra. $\mathrm{N}$. conta que ouviu na televisão que o governo está fazendo um trabalho de prevenção para a saúde masculina e ela foi perguntar para a agente de saúde de seu bairro, mas tanto ela quanto seus supervisores não sabiam de nada, não tinham nenhuma informação. Quando essa mesma agente soube da caravana, ela avisou a N. imediatamente. E agora ela e seu marido estão aqui aguardando pelo atendimento ("Quase aos 40", 18/07/2010).

Não só as esposas, mas também as namoradas e outras familiares são representadas nesse quadro de mulheres atentas à saúde dos parceiros. É o caso do relato sobre A. L., 50 anos:

Ela namora o Sr. M. A., 46 anos, e quando viu a carreta do Movimento pela Saúde Masculina parada no estacionamento do Shopping Internacional de Guarulhos, ela pediu para que ele viesse ser atendido. "No posto de saúde é difícil fazer, porque lá eles só fazem o exame de sangue e eu não confio, eu queria que ele fizesse o exame 
de toque retal" (...). "O doutor foi excelente. Que deus o abençoe. Ele tratou a gente muito bem" - agradeceu a Sra. A. E., que está sempre atenta à saúde do namorado, é ela quem leva os exames dele ao posto de saúde porque ele não tem tempo ("Na dúvida ela fica com os dois", 22/08/2010).

\section{o tio "amarrado" até a Caravana:}

Ele não quer aparecer, por isso, fotos, nem pensar [só há foto dela no post]. P. C. F. veio "amarrado". A sobrinha, R. F., de 28 anos, passava pela Praça Rui Barbosa e soube que haveria atendimento urológico, gratuito, que se iniciaria na quarta-feira. Imediatamente ligou para o tio: "não arruma nada para amanhã que temos compromisso". P. C. veio, trouxe antigos exames e está bem desgostoso. "Ele só vai ao médico em última instância e só veio porque está passando mal", delata ("Trazido pelo braço", 14/04/ 2010).

A luta entre "a mulher que cuida" e "o homem que resiste" ou "reluta", "nega" e "foge" dos cuidados médicos é tema também do post "Empurrãozinho inicial" (19/08/2010). Neste caso, relata-se que, apesar de o paciente em questão, Sr. N., ter ido à Caravana por "livre e espontânea vontade" realizar pela segunda vez o exame de prevenção do câncer de próstata, "A primeira vez foi quando fez 45 anos, mas só porque sua esposa 'pegou no pé'". Neste registro temos ainda uma conclusão geral sobre a importância do papel da mulher na atenção à saúde do homem: "Por mais que o homem esteja começando a se conscientizar de que ele precisa cuidar de sua saúde, a mulher continua sendo a grande responsável pelo empurrãozinho inicial".

Esta opinião é expressa também nos discursos dos urologistas envolvidos com a Caravana. De acordo com o secretário geral da SBU na época, Giacomono Errico, o cenário de pouca procura por ajuda médica por parte dos homens tem mudado graças à ajuda das mulheres: "A mulher está ajudando muito os homens, porque ela fala sobre o assunto, desperta no marido a necessidade de ir ao médico e o acompanha no consultório" ("Movimento pela Saúde Masculina chega a Nova Iguaçu e conscientiza os homens - Portal do Sidney Rezende", 14/04/2010).

Ainda no que se refere ao já legitimado tema das doenças da próstata, cabe mencionar o registro que trata da participação da médica urologista Regina Pacis, que atendeu na Caravana. O postdá destaque exatamente ao fato de a profissional ser mulher $\mathrm{e}$ urologista: "Médica nessa área é coisa rara. Por exemplo, no Recife só tem duas: ela e uma outra. 'No Brasil inteiro, de acordo com as últimas contagens, tem 45 mulheres na urologia', conta Regina Pacis". O registro também faz referência a certas qualidades tidas como femininas, como o carinho e a delicadeza, descritas como positivas quando se trata da realização do exame de toque retal: "Regina já ouviu também muito homem dizer que prefere fazer o exame de toque retal com uma mulher porque ela é mais carinhosa, tem as mãos delicadas. 'É verdade, é verdade!', insiste". o título do post remete ainda ao espanto dos frequentadores da Caravana ao se depararem com a médica urologista: "Essa menina aí é doutora?" (21/05/2010).

Estes e outros relatos que exemplificam a participação da mulher como agente fundamental na promoção da saúde masculina já apontam para uma reificação de funções tradicionalmente atribuídas às mulheres em contraste com os homens. Elas aparecem, mais uma vez, como as principais responsáveis pelo cuidado, inclusive o 
cuidado com os procedimentos de saúde envolvendo parceiros e familiares. Enquanto isso, os homens são retratados como resistentes à tomada de consciência e mesmo à responsabilização pela própria saúde. Nesse quadro, a Caravana parece apelar, exatamente, para uma antiga aliança entre mulheres e médicos como forma de conseguir atingir diretamente os homens. Estes figuram muito mais como vítimas da sua própria masculinidade ou da reprodução de certos padrões de masculinidade que, ao insistirem na força e na resistência, impedem ou dificultam que eles cheguem mais prontamente aos serviços de saúde. ${ }^{16}$

\section{b) "Ela foi a porta-voz do casal"}

O segundo conjunto de observações em destaque aqui se refere à importância e à especificidade da participação feminina no que diz respeito às disfunções sexuais e, particularmente, à disfunção erétil. Em relação à disfunção erétil, a mulher é apresentada não apenas como aquela que "leva", "empurra" ou "arrasta" o homem ao médico, ou que simplesmente o conscientiza da necessidade de cuidar da sua saúde, mas seu papel se sobressai também a partir da sua participação fundamental no momento da consulta médica. A diferença entre as categorias acionadas em um e outro caso é significativa e reveladora do universo semântico em questão. No quadro das doenças da próstata, é admissível e mesmo esperado que as mulheres cumpram o que seria o seu papel tradicional de "arrastar" os homens aos médicos. Trata-se de doenças graves e reconhecidamente ameaçadoras. Aos homens restaria se submeterem com resigna

ção a esta ordem, apesar dos constrangimentos envolvidos. Já quando se trata da disfunção

erétil, a mulher se converte na própria capacidade de expressão ou comunicação do problema, como se homens não fosse esperado, em hipótese alguma, a revelação "pública", mesmo que no consultório, de dificuldades envolvendo o sexo. Parece que nesse nível reforçam-se não apenas as diferenças de gênero traduzidas nos termos de cuidado e resistência, mas também o estereótipo mais geral da mulher como aquela que "fala", em contraste com o homem como aquele que oculta e controla a expressão de dificuldades.

No mesmo sentido, é possível enfatizar que, se nas descrições em relação à postura dos homens no que se refere às doenças da próstatatêm destaque termos como"vergonha" e "preconceito", no que diz respeito à disfunção sexual entram em cena expressões como "timidez" e "mentira". Os homens teriam muita dificuldade em tocar no assunto dos problemas de ereção e tenderiam a mentir sobre suas performances. Talvez em função disso os depoimentos a este respeito dos homens que participaram da Caravana sejam escassos. Como é possível perceber nos relatos que se seguem, os médicos urologistas

ão atribuir às mulheres o mérito de expor a verdade sobre o assunto nos consultórios.

Nota-se ainda que as referências sempre se mantêm no marco das relações heterossexuais e monogâmicas e que a sexualidade ou mesmo a prática sexual se refere exclusivamente à penetração da mulher pelo homem. 
$m$ dos registros traz uma entrevista com o médico urologista Carlos Antonio de Souza, que critica a atitude dos homens que demoram a procurar ajuda e vão sozinhos ao consultório para tratar da disfunção erétil: "Os homens, em geral, só procuram o urologista para tratar a disfunção erétil três anos após instalada a doença. E, geralmente, o homem vai sozinho ao consultório". E isso "por questões culturais, por se sentir envergonhado em procurar o médico para tratar disso". Ainda de acordo com o médico, "Em geral, não há compartilhamento do problema com a parceira". E, se as mulheres são as grandes responsáveis por levar os homens aos médicos, se há um problema que não é explicitado ou comunicado, rompe-se a cadeia que faria com que eles chegassem aos consultórios ("Carlos Antônio de Souza, presidente da SBUPernambuco", 21/05/2010).

"A conscientização que vem das fábricas e do lar" (11/08/2010) propõe-se a conexão direta entre a inibição do homem em face da disfunção erétil, a mentira deste ao médico e o papel da mulher no que diz respeito a essa situação. Desta vez, utiliza-se o depoimento do urologista integrante da SBU de São Paulo, Marco Antônio Fioravante:

Ele conta que o papel da mulher é fundamental para incentivar o homem na prevenção de sua saúde, pois muitas vezes ele pergunta aos seus pacientes se eles têm problema de disfunção erétil e a maioria responde: "Está tudo bem". Mas quando eles voltam ao consultório com os exames prontos, eles falam: "Doutor, o senhor fez uma pergunta e eu acho que não entendi direito". É quando o doutor conversa com o paciente e ele realmente tem a disfunção erétil. $O$ que acontece é que quando ele chega em casa e diz para a esposa que não falou da disfunção, ela o incentiva a falar e, às vezes, ela até vai junto à consulta para expor o quadro.

50 A participação da mulher explicitamente rotulada de "porta voz do casal" é ainda descrita no registro "O que dominou foi a disfunção erétil" (22/08/2010), que traz o depoimento de três médicos urologistas que atenderam na Caravana (André Mota, Plínio Marcelo Sorti, Orlando Sanches). O relato do urologista Orlando Sanches é enfático quanto a este ponto: Ele também fala da importância da mulher ao lado do homem:

Veio uma mulher para o atendimento com o marido. Ele, por uma inibição muito grande, não consegue explicar tudo que ele tem, então foi importante a presença da mulher para explicar toda a parte da sexualidade do casal. Ela foi a porta-voz do casal. Ele não sabia nem que caminho seguir. Ela veio para falar porque ele não fala, ele esconde os fatos, é inibido.

51 O protagonismo das mulheres neste tipo de situação aparece também em virtude de outros aspectos, como a percepção de que estariam muito mais exigentes no que diz respeito às relações sexuais. Por este motivo, elas estimulariam os homens a buscarem a orientação de um médico urologista. De acordo com o relato do urologista Daniel Kanda Abe, que atendeu na Caravana, "o que deu pra perceber é que a maioria dos homens vem por recomendação das parceiras. Elas éque buscam informação". Isto estaria acontecendo porque "agora as parceiras estão exigindo mais dos parceiros, há muita queixa da parte sexual [...]. A maioria destas queixas está relacionada à ejaculação precoce e àdisfunção erétil". Em suma: "como as parceiras estão mais exigentes e havendo maior interação entre o casal, eles estão conseguindo expor melhor o problema" ("Participação em dose dupla", 29/08/ 2010).

Outra forma em que as mulheres aparecem como agentes centrais na questão dos problemas sexuais masculinos é quando elas são consideradas a origem das dificuldades 
do casal. Isto é exemplificado no relato "Depoimento: tenho prazer, mas não tenho ereção" (22/05/2010), no qual se expõe a história de um paciente que, mesmo "procurando ajuda médica e psicológica" para tratar de sua disfunção erétil, "não obteve resultado positivo". Isto "porque a solução do problema não depende só dele". A questão em jogo é a recusa da esposa em aceitar ajuda para tratar os problemas: "Procurei ajuda psicológica para nós. Mas ela [a esposa] inicia e não continua... Ela não quer mudar, é muito restrita a certas coisas; acha que as coisas que a psicóloga fala são ousadas demais". Neste caso, o fato de a mulher não querer participar das consultas psicológicas e não aceitar o tratamento é destacado como uma atitude negativa que se refletiria diretamente na disfunção erétil do marido. ${ }^{17}$

Por meio destes exemplos, é possível perceber, por um lado, a relevância da capacidade de ereção para a definição da sexualidade e da própria identidade masculina. A apresentação mais geral dos objetivos da Caravana e os registros são enfáticos em apontar para os problemas associados à disfunção erétil na vida dos homens, inclusive destacando como esta dificuldade pode estar associada a doenças extremamente importantes, como diabetes e doenças cardiovasculares. Além disso, como se pressupõe que a sexualidade masculina seja restrita à capacidade de penetração do pênis e também que esta seja sempre alvo de preocupações generalizadas entre os homens, seria a forma de atraí-los para o universo da atenção àsaúde. Uma vez que chegassem a procurar ajuda médica para tratar da disfunção erétil, poderiam ser encaminhados para todos os outros procedimentos necessários ao seu bem-estar (Rohden, 2012).

Por outro lado, mais uma vez se destaca a centralidade das mulheres, cujo papel pode variar de fator de risco a responsáveis não apenas pela ida dos homens ao médico, mas também para garantir que a verdade seja dita. Aparece uma concepção naturalizada de que os homens mentiriam ou tenderiam a ocultar a verdade sobre os seus problemas sexuais, enquanto as mulheres agiriam no sentido de explicitar as dificuldades, não tendo vergonha ou mentindo acerca do assunto. A responsabilidade delas pelo cuidado parece se estender, portanto, até o plano da sexualidade, pensada sempre, como já foi dito, em termos heterossexuais e mesmo monogâmicos.

\section{Novas campanhas, velhas diferenças}

A forma como a Caravana pela Saúde Masculina aciona determinadas concepções de gênero e sexualidade remete à discussão proposta neste artigo acerca da relação entre o desenvolvimento de tecnologias e a ênfase em certos valores culturais associados a dimensões identitárias. A Caravana é tomada aqui como um artefato tecnológico que envolve uma rede complexa de associações e agentes variados que pretende intervir na atenção à saúde do homem, promovendo conscientização e acesso a diagnósticos e recursos terapêuticos. Mas, para fazer isso, os responsáveis pela campanha acionam marcadores muito particulares que se expressam na forma como os temas são escolhidos e apresentados no movimento como um todo e, inclusive, no uso que se faz dos depoimentos e das imagens dos "usuários" no blog da Caravana.

Dentre os vários aspectos possíveis de serem retomados, dois serão alvo de destaque aqui. $\mathrm{O}$ primeiro se refere à insistente referência ao sexo, traduzido na função erétil, como central para a identidade masculina e mesmo para a saúde de um modo geral. A atividade sexual e mais precisamente a capacidade de ereção estariam associadas ao bem-estar e àausência de doenças, além de simbolizarem a própria ideia de vida e 
masculinidade. 0 segundo diz respeito à preeminência da apresentação das mulheres como as responsáveis pelo cuidado em saúde de um modo geral. Elas não apenas levam e devem continuar levando os homens ao médico, mas também são vistas como responsáveis por garantir que eles façam os exames e digam a verdade durante as consultas. Elas devem estender o seu papel de cuidadoras do lar e da família, enquanto é esperado deles que aceitem o "empurrãozinho" e cheguem até o médico. Mesmo nos casos em que se fala em "conscientização", o papel da mulher continua sendo chave: ela como a grande mediadora entre as orientações médicas e os homens.

Quando retomamos a história da contracepção masculina descrita por Oudshoorn (2003, 2004), referida aqui como foco de contraste analítico, é possível avançar um pouco mais nesta argumentação. A autora relata, a partir de uma vasta pesquisa histórica, como as tecnologias de contracepção ficaram relegadas às mulheres, dessa forma reforçando-se a ideia de que a reprodução e a contracepção seriam assuntos exclusivamente femininos. Por outro lado, a inexistência de tecnologias comercializadas e a desresponsabilização dos homens caminharam lado a lado no reforço da noção de que este não seria um assunto masculino.

Cabe destacar ainda que um dos aspectos sempre levantados nos debates em torno dos métodos contraceptivos masculinos seriam as possíveis interferências desses artefatos na sexualidade masculina, como poderia ser o caso, por exemplo, dos métodos hormonais baseados em testosterona. De modo contrastante, a questão da interferência dos contraceptivos na sexualidade feminina, embora admitida, não foi tema de grandes investigações até a década de 1990. Pode-se supor a partir daí que, mais uma vez, as mulheres aparecem como mais associadas à reprodução e ao cuidado (inclusive contraceptivo ou de planejamento familiar), enquanto os homens são mais associados ao livre exercício da sexualidade, sem necessariamente serem levados a considerar as questões que envolvem a reprodução. No que se refere à Caravana, é necessário chamar a atenção para o fato de que as questões envolvendo reprodução e contracepção não aparecem como tópicos abordados, reforçando a ideia de que este não seria um assunto masculino, mesmo quando se está tratando da relação entre sexo e saúde. ${ }^{18}$

É interessante notar que vários estudos têm indicado como, de um modo geral, enquanto as mulheres têm passado por um processo histórico de mais longo tempo, envolvendo a medicalização dos seus corpos e comportamentos, sobretudo pela ênfase na reprodução, os homens só mais recentemente estariam sendo envolvidos em processo semelhante (Rohden, 2009). No século XX, a trajetória de medicalização da sexualidade teria se caracterizado muito mais por um foco no homem e na circunscrição da sexualidade masculina à disfunção erétil. Por meio de uma problematização mais geral que articula sexualidade e idade como dimensões fundamentais do sujeito moderno, Marshall e Katz (2002) destacam a importância das culturas de estilo de vida do final do século passado, como a ênfase na saúde, na atividade e no não envelhecimento para o processo que vai dar origem a um vasto campo de estudos e intervenções em torno da capacidade de ereção. Passa-se a dar relevo à atividade sexual como condição indispensável para uma vida saudável e à capacidade erétil como definidora da virilidade durante todo o curso da vida masculina (Marshall \& Katz, 2002; Marshall, 2006).

60 Nesse novo contexto, de acordo com Loe (2001), o Viagra surge como uma tecnologia material e cultural que está relacionada com a construção de uma nova possibilidade de intervenção no corpo masculino, em contraste com a tradicional história de 
intervenção médica no corpo das mulheres. Isto só tem se tornado possível graças à propagação de uma ideia de masculinidade em crise, ilustrada sobretudo com a metáfora da ereção. A noção de que a ereção, símbolo da virilidade e da identidade masculina, é efetivamente instável e sujeita a vários tipos de percalços parece ganhar cada vez mais notoriedade. E é justamente para combater essa falta de controle ou imprevisibilidade do corpo masculino que a indústria oferece um recurso como o Viagra, capaz de garantir a expectativa de uma performance sempre melhor (Grace et al., 2006; Vares \& Braun, 2006). Ao mesmo tempo, as indústrias farmacêuticas promoveram e ideia de que a disfunção erétil seria um importante problema de saúde, tornando-se cada vez mais um tópico aceitável do discurso público, o que também levaria a uma maior procura pelo tratamento (Lexchin, 2006).

61 Teríamos então uma medicalização da sexualidade focada nos homens em contraste com uma medicalização da reprodução centrada nas mulheres, o que reforça a dimensão do cuidado associado ao feminino e a resistência ao masculino. É possível mencionar aqui como foi recorrente, nos eventos em torno dos 50 anos da pílula contraceptiva, em 2010, a sua descrição como responsável por uma verdadeira "revolução" na sexualidade feminina, enquanto se ponderava sobre os possíveis problemas associados ao seu uso, especialmente no que se refere aos riscos à saúde das mulheres. O curioso é que, nas comemorações do aniversário de 15 anos do Viagra (2013), o termo "revolução" também foi empregado, desta vez para descrever os impactos do medicamento na disfunção erétil da sexualidade masculina. E parecia não haver necessidade de ponderações ou ressalvas em relação ao seu uso, assim como não se notam movimentos mais gerais de debate em torno da medicalização da saúde e da sexualidade dos homens. ${ }^{19}$

Retomando ainda a análise da Caravana como evento produtor de tecnossociabilidade, nos termos propostos por Oudshoorn $(2003,2004)$, e sua relação com a dimensão cultural, é possível afirmar que se torna evidente como distintos aspectos envolvendo criação e reprodução são acionados. Se, por um lado, percebe-se a intenção de promover um "novo" comportamento nos homens, levando-os a se conscientizarem da importância dos cuidados com a saúde, por outro, reforça-se que o seu engajamento passa em primeiro lugar pelo recurso às mulheres como as responsáveis por encorajálos ou mesmo encaminhá-los ao médico. Se a explicitação do tema da sexualidade, sua colocação como tópico legítimo de discurso e de tratamento podem, em certo sentido, ser compreendidas como inovação, em outro, os valores associados ao reforço da heterossexualidade, do sexo penetrativo, da potência sexual como quase exclusivamente responsáveis pela virilidade e a identidade masculina dão ênfase a dimensões mais tradicionais associadas às distinções de gênero.

\section{BIBLIOGRAFIA}

BUTLER, Judith. 1995. "Melancholy gender/refused identification”. In: M. Berger, B. Wallis, \& S. Watson (orgs.). Constructing masculinity. London: Routledge. pp. 21-37. 
CALLON, Michel \& LAW, John. 1982. "On interests and their transformation: enrollment and counter-enrollment”. Social Studies of Science, 12:615-625.

CALLON, Michel.1985. "Some elements of a Sociology of Translation: domestication of the scallops and the fishermen of St. Brieuc Bay". In: J. Law (ed.). Power, action and belief: Sociological Review Monograph, n. 32. London: Routledge \& Kegan Paul. pp.196-230.

CARRARA, Sérgio, RUSSO, Jane \& FARO, Livi. 2009. “A política de atenção à saúde do homem no Brasil: os paradoxos da medicalização do corpo masculino". Physis. Revista de Saúde Coletiva, 19 (3): 659-678.

COUTO, Marcia T., PINHEIRO, Thiago \& VALENÇA, Otávio. 2010. “O homem na atenção primária à saúde: discutindo (in)visibilidade a partir da perspectiva de gênero". Interface. Comunicação, Saúde e Educação, 14:257-270.

GOMES Romeu. 2008. Sexualidade masculina, gênero e saúde. Rio de Janeiro: Fiocruz.

(org.). 2011. Saúde do Homem em debate. Rio de Janeiro: Fiocruz.

GRACE, Victoria, POTTS, Annie, GAVEY, Nicola \& VARES, Tina. 2006. "The discursive condition of Viagra". Sexualities, 9 (3):295-314.

LATOUR, Bruno. 1988. Science in action. Cambridge: Harvard University Press.

1990. “Drawing things together”. In: Michael Lynch \& Steve Woolgar (orgs.). Representation in Scientific Practice. Cambridge: MIT Press. pp.19-68.

2005. Reassembling the social: an introduction to actor-network theory. New York: Oxford University Press.

LAW, John. 1987. “Techonology, closure and heterogeneous engineering: the case of the Portuguese expansion". In: W. Bijker, T. Pinch \& T.P. Hugues (eds.). The social construction of technological systems. Cambridge: MIT Press. pp.111-134.

LEXCHIN, Joe. 2006. "Bigger and better: how Pfizer redefined erectile dysfunction". Plosmedicine, 3 (4):1-4.

LOE, Meika. 2001. "Fixing broken masculinity: Viagra as a technology for the production of gender and sexuality". Sexuality and Culture, 5 (3):97-125.

2004. The rise of Viagra: how the little bleu pill changed sex in America. New York: New York University Press.

MARSHALL, Barbara \& KATZ, Stephen. 2002. "Forever functional: sexual fitness and the ageing male body". Body and Society, 8 (43):43-70.

MARSHALL, Barbara. 2006. "The new virility: Viagra, male aging and sexual function". Sexualities, $9(3): 345-362$.

OUDSHOORN, Nelly. 2004. "Astronauts in the sperm world: the renegociation of masculine identities in discourses on male contraceptives". Men and masculinity, 6:349-367.

2003. The male pill: a biography of technology in the making. Durham: Duke University Press.

PANVEL. Ano 9, n. 5, 01 a 30/06/2010.

PINHEIRO Thiago, COUTO, Marcia \& SILVA, Geórgia. 2011. “Questões de sexualidade masculina na atenção primária à saúde: gênero e medicalização”. Interface, 15:845-858.

RABINOW, Paul. 1992. "Artificiality and enlightenment: from sociobiology to biosociality". In: J. Crary \& S. Kinter (orgs.). Incorporations. New York: Zone. pp. 234-52. 
ROHDEN, Fabíola. 2012. "Capturados pelo sexo: a medicalização da sexualidade masculina em dois momentos”. Ciência \& Saúde Coletiva, 17(10):2645-2654.

ROHDEN, Fabíola. 2011. “'O homem é mesmo a sua testosterona': promoção da andropausa e representações sobre sexualidade e envelhecimento no cenário brasileiro". Horizontes Antropológicos, 17:161-196.

ROHDEN, Fabíola. 2009. "Diferenças de gênero e medicalização da sexualidade na criação do diagnóstico das disfunções sexuais”. Revista Estudos Feministas, 17(1):89-109.

ROHDEN, Fabíola \& TORRES, Igor. 2006. "Le champ actuel de la sexologie au Brésil: considérations initiales". Sexologies, 15(1):64-71.

SCHRAIBER Lilian, GOMES, Romeu \& COUTO, Marcia. 2005. "Homens e saúde na pauta da Saúde Coletiva". Ciência e Saúde Coletiva, 10 (1):7-34.

STAR, Susan Leigh \& GRIESEMER, James R. 1989. “Institutional ecology, 'translations' and boundary objects: amateurs and professionals in Berkeley's Museum of Vertebrate Zoology, 1907-39". Social Studies of Science, 19 (3):387-420.

VARES, Tina. \& BRAUN, Virginia. 2006. "Spreading the word, but what word is that? Viagra and male sexuality in popular culture". Sexualities, 9 (3):315-332.

Sites consultados:

http://www.abeis.org.br. Acesso em: 23/03/2011.

http://www.bostonmedicalgroup.com.br. Acesso em: 19/08/2013.

http://www.movimentopelasaudemasculina.com.br/. Acesso em: 5/03/2011.

\section{NOTAS}

1. Este trabalho é resultado do projeto de pesquisa "Gênero, sexualidade e envelhecimento na promoção de novos diagnósticos médicos" (apoiado pelo CNPq), que se destinou a mapear a criação e a promoção dos diagnósticos relativos ao processo de envelhecimento de homens e mulheres na sua inter-relação com as manifestações associadas à sexualidade, tendo como referência a dimensão das relações de gênero. Agradeço a Gabriela Cordesonsi da Fonseca e Eduardo Doering Zanella que colaboraram na pesquisa como bolsistas de iniciação científica.

2. A ação havia sido bastante divulgada na cidade por meio de diversas estratégias, como a reprodução das peças publicitárias (incluindo as imagens e as informações já descritas) na revista de divulgação da principal rede de farmácias de Porto Alegre, distribuída gratuitamente. Ver revista Panvel (2010).

3. Trabalhos recentes têm se dedicado a mapear a atenção à saúde do homem no Brasil em suas várias facetas e implicações, como: Gomes (2011, 2008); Schraiber, Gomes \& Couto (2005); Pinheiro, Couto \& Silva (2011); Couto, Pinheiro \& Valença (2010). Em relação especificamente à criação de uma política de atenção à saúde do homem no Brasil, consultar Carrara, Russo \& Faro (2009).

4. É de se notar que o slogan "Sexo é vida" constitui-se na referência central acionada pelo Boston Medical Group, "líder em saúde masculina”, que detém uma gigantesca rede de clínicas em vários países do mundo. Ver: http://www.bostonmedicalgroup.com.br/? gclid=CN3iyLOoirkCFQai4Aod8XkA0A. Acesso em: 19/08/2013.

5. Sigo aqui a perspectiva adotada por Latour $(1987,2005)$, Star \& Griesemer (1989), Callon (1985), Law (1987) e Callon \& law (1982). 
6. O Movimento pela Saúde Masculina realizou eventos em Porto Velho e em Rio Branco em março de 2011, mas não há informações sobre a continuidade da Caravana. Em função disso, as análises empreendidas neste artigo referem-se à atuação do Movimento pela Saúde Masculina em 2010.

7. O sítio www.movimentopelasaudemasculina.com.br esteve disponível entre 2010 e 2011 e posteriormente foi desativado.

8.

São Paulo, Rio de Janeiro e Brasília foram cidades que se repetiram no percurso da Caravana pela Saúde Masculina.

9. No decorrer deste artigo, serão sempre indicados os títulos dos registros postados no sítio, bem como as respectivas datas de publicação. Todo o material foi acessado em www.movimentopelasaudemasculina.com.br, em 05/03/2011.

10. No sítio do Movimento, boa parte dos registros fotográficos incluíam mulheres, havendo mesmo casos em que apenas elas estavam presentes nas imagens divulgadas. Conforme www.movimentopelasaudemasculina.com.br. Acesso em: 05/03/2011.

11. Disponível em www.movimentopelasaudemasculina.com.br/encontre-um-medico. Acesso em: 05/03/2011.

12. Para uma análise específica da promoção do diagnóstico da andropausa ou DAEM (Distúrbio Androgênico do Envelhecimento Masculino), ver Rohden (2011).

13. Cabe acrescentar que este tema aparecia também em outros eventos públicos ou campanhas realizadas pelos urologistas integrantes da SBU e mesmo de outras instituições, como a Associação Brasileira para o Estudo da Inadequação Sexual (ABEIS). Em entrevista à Rádio CBN com a jornalista Lilian Ribeiro, realizada em 15/05/2010, o presidente da ABEIS (e membro da SBU) Paulo Brito Cunha reafirmava que quem mais leva o homem ao médico são as esposas, que são as "mais interessadas no interesse dele", enquanto "o homem é mais mentiroso, é mais fanfarrão, mais loroteiro, mais cascateiro". Disponível em: www.abeis.org.br. Acesso em: 23/03/2011.

14. Disponível em: www.movimentopelasaudemasculina.com.br. Acesso em: 05/03/2011.

15. Embora o sítio do Movimento reproduza o nome completo dos usuários, optei por manter apenas as iniciais.

16. Para uma discussão acerca de como certa vulnerabilidade masculina acaba sendo promovida nos discursos envolvendo a elaboração da Política Nacional de Atenção Integral à Saúde do Homem, ver Carrara, Russo \& Faro (2009).

17. Em etnografia de congressos de sexologia e medicina sexual, especialmente em conferências proferidas por médicos urologistas, mais de uma vez ouvi a referência à ideia da mulher como "fator de risco" para a disfunção erétil do "marido". Certa vez, em um congresso latinoamericano, um urologista argentino explicou, com a ajuda de imagens, que se a mulher do paciente com disfunção erétil fosse "feia" e "gorda", não adiantaria nem usar os recursos farmacológicos para tentar resolver o problema. Por outro lado, se ela fosse tão atraente como a atriz Angelina Jolie, o médico deveria dispensar o paciente e convidar a esposa para um jantar. Certamente se tratava de uma anedota, contudo, representa a forma como as concepções de gênero e sexualidade podem ser acionadas neste campo.

18. Caberia acrescentar que em pesquisa nas principais revistas do campo da sexologia no Brasil, que inclui uma participação de destaque dos urologistas ligados ao ramo da medicina sexual, o tema da contracepção também não está presente. Trata-se da Revista Brasileira de Estudos em Sexualidade Humana, editada pela Sociedade Brasileira de Estudos em Sexualidade Humana (SBRASH), com números de 1990 a 2003; da Revista Terapia Sexual, do Instituto Paulista de Sexualidade (InPaSex) e do Centro de Estudos do Comportamento e Sexualidade (CEPCoS), publicada desde 1998; e da Revista Scientia Sexualis, do Mestrado em Sexologia da Universidade Gama Filho (UGF), com números de 1997 a 2001. Do total de 645 artigos analisados nos períodos 
indicados nas três revistas, apenas seis se referem diretamente à contracepção. Ver Rohden \& Torres (2006).

19. Ver, por exemplo, a matéria publicada no jornal $O$ Globo, em $06 / 07 / 2013$, intitulada "Os 15 anos da pílula azul", que traz este tipo de comparação: “Como que respondendo aos anseios da sociedade por mudanças comportamentais, a pílula anticoncepcional foi lançada em 1960, quando o movimento feminista ganhava força no mundo todo e a liberdade sexual era uma de suas bandeiras. Quase 40 anos depois, uma outra pílula viria novamente responder às demandas de uma população que se tornava cada vez mais longeva e buscava formas de viver esses anos extras em plenitude. Se o contraceptivo abriu as portas para o sexo por prazer, é possível dizer que o Viagra garantiu a possibilidade de que esse prazer se estendesse por muito mais tempo". Disponível em: http://oglobo.globo.com/saude/os-15-anos-da-pilula-azul-8937062. Acesso em: 01/11/2013.

\section{ÍNDICE}

Keywords: Male health, gender relations, sexuality, intervention technologies.

Palavras-chave: Saúde masculina, relações de gênero, sexualidade, tecnologias de intervenção.

\section{AUTOR}

\section{FABÍOLA ROHDEN}

UFRGS. Fabíola Rohden é professora do Programa de Pós-Graduação em Antropologia Social, coordenadora do Núcleo de Pesquisas em Antropologia do Corpo e da Saúde da UFRGS e pesquisadora do CNPq. Contato: fabiola.rohden@gmail.com 